Ärztliche Erfahrung beschränkt sich nicht auf medizinisches Fachwissen.

Sie entsteht auch aus den mehr oder minder alltäglichen, heiter, ärgerlich oder nachdenklich stimmenden Erlebnissen mit Patienten, Kollegen und Mitarbeitern. Senden Sie uns Ihre Geschichte an: cornelius.heyer@springer.com.

\title{
Diesen Fratzenschneider habe ich beleidigt
}

Ein Patient kam mit einem Augenproblem zu mir in die Praxis, das er allerdings nur recht mysteriös beschreiben konnte. Ich versuchte, aus seinen Angaben eine Verdachtsdiagnose zu stellen, wollte aber die Bindehäute einmal genauer beäugen. Deshalb ging ich mit ihm zur Balkontür, wo mir das Tageslicht das Areal erhellen sollte.

Ich forderte den Patienten auf, einmal selbst seine Unterlider nach unten zu ziehen. Als er dies tat, fühlte ich mich schlagartig zurückversetzt in eine vergangene Zeit, nämlich als ich mit meinem Sohn eine seiner liebsten Kinderkassetten angehört hatte. Auf der wurde eine Geschichte von zwei Jungen erzählt, die sich ständig stritten. Die Mutter schlug den Hitzköpfen vor, sich doch lieber gegenseitig Fratzen zu schneiden. Dies brachte die Kinder zum Lachen, und der Streit war behoben.

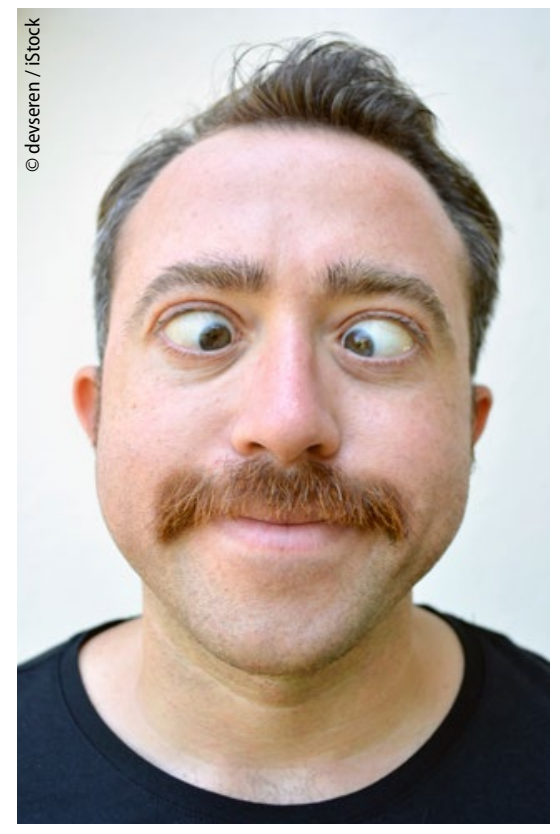

Gesichtsakrobatik induziert Lachanfall stört Arzt-Patienten-Verhältnis.
Am Fenster meiner Praxis überkam nun auch mich ein Lachanfall ob der dargebotenen Gesichtsakrobatik, und ich konnte meinen Patienten gerade noch auffordern, schnell die Augen zusammenzukneifen, auf dass er es nicht bemerke. Aber es war hoffnungslos. Mir ging es wie dem Schweizerischen Bundesrat Hans-Rudolf Merz, der vor dem Parlament seine Ausführung über „Bündnerfleisch" wegen eines Lachanfalls nicht vortragen konnte. Was für eine absurde Situation für einen Politiker.

Der Patient fand das ganze leider nicht so lustig, und als ich ihm am Ende meiner glorreichen Untersuchung dann noch mitteilte, dass er mit seinen 45 Jahren „altersweitsichtig“ sei, entglitten ihm auch noch die restlichen Gesichtszüge. Ich glaube kaum, dass ich die schicke neue Lesebrille zu Gesicht bekomme. -

Dr. Luise Hess, Darmstadt

\section{Darauf ist selbst Hahnemann nicht gekommen}

_ Schon mehrfach habe ich es zugeben müssen: Ich betrachte die Homöopathie mit Argwohn. Ich habe den wissenschaftlich nicht ganz unbegründeten - Verdacht, dass ihre Wirkung nicht über Placeboniveau hinaus geht. Dennoch bietet sie in der tagtäglichen Versorgung eine gute Möglichkeit, interessierten Patienten eine Therapie anzubieten, die ihnen zumindest keinen Schaden zufügt.
Nun gibt es eine Reihe von Anhängern der Homöopathie, die am liebsten alles selber machen und eine ganze Batterie an Globuli zu Hause haben. Oft begegnen sie uns Ärzten skeptisch und greifen auf ihre Sammlung nicht nur selber gern $\mathrm{zu}$, sondern verteilen sie auch in Büro, Familie und Bekanntenkreis freigiebig. Wer „heilt“, hat schließlich Recht - homöopathisches Wissen oder gar eine ausführliche
Anamnese sind dann ja gar nicht nötig. Wenn es dann kompliziert wird, fragen sie nach, welche Nosode nun die geeignete sein könnte.

Die absurdeste Frage diesbezüglich habe ich auf einer Internetseite mit Arztbetreuung gefunden. Da wollte jemand wissen: „Gibt es eine homöopathische Pille danach?" Dem bleibt wohl nichts hinzuzufügen.

Dr. Frauke Höllering, Arnsberg 